\title{
The evaluation of sexual dysfunction in male patients with migraine and tension type headache
}

\author{
Durdane Aksoy ${ }^{1 *}$, Volkan Solmaz ${ }^{1}$, Betul Cevik ${ }^{1}$, Yusuf Gencten ${ }^{2}$, Fikret Erdemir ${ }^{2}$ and Semiha Gulsum Kurt ${ }^{1}$
}

\begin{abstract}
Background: Erectile dysfunction (ED), defined as the inability to achieve or maintain an erection sufficient for satisfactory sexual performance, is a common condition. The psychological, hormonal, neurogenic and arterial pathologies, medications, chronic diseases have been reported in the etiology of the ED. This paper aims to study sexual dysfunction in the male patients with migraine and Tension type headache $(T H H)$.

Methods: 30 migraine cases (Group M), 31 TH cases (Group T) and 30 control cases (Group C) were included in the study. Patients were evaluated with medical history, physical examination, body mass index (BMI), Beck Depression Inventory, biochemical analysis and hormone profiles. ED was evaluated via International Index of Erectile Function Scale (IIEF). In statistical analysis, variant analysis, post-hoc tukey test, Pearson correlation test, $t$-test, and fisher's exact chi-square test were used.

Results: The patients' mean age was $34.96+/-1.30,35.54+/-1.52$ and $32.26+/-1.38$ for group $M, T$ and $C$, respectively. There was no significant difference between the groups in terms of testosterone levels. Mean IIEF scores was $19.83+/-2.2,20.39+/-1.35$ and $27.83+/-0.34$ in groups $M, T, C$. When $M$ and T groups were compared with group C, there were significant differences, and there was no statistical difference when $\mathrm{T}$ and $\mathrm{M}$ groups were compared to each other. Beck Depression Scores were not significantly different in groups $\mathrm{M}, \mathrm{T}$ and $\mathrm{C}$.

Conclusion: In this study, it was shown that, migraine and $T H$ affects the sexual functions negatively in male patients. Chronic diseases may cause sexual disorders in patients because of despair, guilt, and fear of death or pain. Our results suggest that, along with the effect of chronic disease and pain, there must be other complicated factors exist causing the development of SD in patients with migraine and $\mathrm{TTH}$.
\end{abstract}

Keywords: Migraine, Tension type headache, Erectile dysfunction, International Index of Erectile Function Scale

\section{Background}

Erectile dysfunction (ED), defined as the inability to achieve or maintain an erection sufficient for satisfactory sexual performance [1], is a common condition, with a reported prevalence of $52 \%$ in men aged 40 to 70 years in the United States and $49 \%$ in men aged 50 to 80 years in Europe [2,3]. For normal penile erection the integration of normal psychological, neurological, and normal vascular processes are required. Several factors can disrupt the normal physiologic mechanisms involved in

\footnotetext{
* Correspondence: dbekar@yahoo.com

'Department of Neurology, Gaziosmanpasa University Faculty of Medicine, Tokat, Turkey

Full list of author information is available at the end of the article
}

penile erection. In this context, the psychological, hormonal, neurogenic and arterial pathologies, medications, iatrogenic causes, and also systemic and chronic diseases have been reported in the etiology of the ED. Chronic diseases include diabetes mellitus, chronic renal failure, chronic obstructive lung disease, arthrosis, collagen tissue diseases, chronic hepatitis and other chronic infections, hypertension, multiple sclerosis and Behçet's disease [4-7].

Migraine is also a chronic disease and one of the most common causes of primary headache along with tension type headache $(\mathrm{TTH})$. Sensitivity to stress factors, significant degradation in quality of life and workforce loss in communities are the common features of both 
headache types, and can noticeably affect social life in many situations. Sexual functions are also affected, and existence of sexual dysfunction can cause lack of selfconfidence, social withdrawal, divorces and other social problems by the effect on the quality of life of both the patient and his partner $[8,9]$. In accordance with these findings, sexual dysfunction is noted in male cases of all other chronic diseases along with migraine [10].

This paper aims to study sexual dysfunction in the most common primary headache causes, TTH and migraine.

\section{Methods}

Between January, 2012 and December, 2012, 30 migraine type headache cases (Group M), 31 tension type headache cases (Group T) and 30 control cases (Group C) were included in the study after informed consent was obtained. All individuals in the patient and control groups were married. The patients' condition had been there for at least 6 months with no prophylactic treatment. Patients were evaluated with detailed medical history, physical examination, body mass index (BMI), routine hematologic and biochemical analysis, liver function tests and hormone profiles (Testosterone). ED was evaluated via International Index of Erectile Function Scale (IIEF). IIEF is one of the most commonly used tests for the investigation of patients with sexual dysfunction. In this test, answers receive points between 0 and 5. Erectile dysfunction is classified as severe ED (110 points), intermediate ED (11-16), intermediate-mild ED (17-21 points), mild ED (22-25 points) and nonerectile dysfunction (26-30) according to answers to 15 questions [11].

Patients with psychosis or similar psychiatric disorders, antidepressant, anticonvulsant, and antipsychotic drug use, chronic disorder, chronic pain, BMI greater than 30, chronic alcohol and tobacco use, history of pelvic operation, and metabolic, endocrine, or neurologic disorders were excluded from the study. All patients were analyzed with the Beck Depression Inventory for their psychiatric state. The Beck Depression Inventory was developed by Beck in 1961. It aims to evaluate the level of emotional, cognitive and motivational symptoms and has 21 questions. Each part of the test contains questions that express a behavioral pattern specific to depression, scaled from least to greatest. In all cases, headache and its classification were made by a neurology specialist according to International Headache Society (IHS) criteria. The hospital ethics committee approved the study, and written informed consent was obtained from each patient after the nature and purpose of the study was fully explained. All experiments were performed in accordance with the Declaration of Helsinki.
When presenting data, percentage and standard deviation were used. In statistical analysis, variant analysis, post-hoc tukey test, Pearson correlation test, $t$-test, and fisher's exact chi-square test were used. All statistical analyses were made with SPSS-15 software. All tests were found significant for $\mathrm{p}<0.05$.

\section{Results}

The mean age of the patients was $34.96 \pm 1.30$ year, $35.54 \pm 1.52$ year and $32.26 \pm 1.38$ year for group $M$, group $\mathrm{T}$ and group $\mathrm{C}$, respectively. There was no statistical significant difference in age distribution $(p=0,22)$. The average number of days with headache per month was $4.06 \pm 3.35$ in Group $\mathrm{M}$ and $3.36 \pm 2.28$ in group $\mathrm{T}$. Mean BMI of group $\mathrm{M}$, group $\mathrm{T}$ and group $\mathrm{C}$ were $24.68 \pm 0.56,27.06 \pm 0.79,25.85 \pm 0.49$ respectively. Total testosterone levels were $4.82 \pm 0.37$ in group $\mathrm{M}, 4.51 \pm$ 0.34 in group $\mathrm{T}$ and $4.59 \pm 0.30$ in group $\mathrm{C}$ and there was no statistical difference between groups (Table 1). Mean IIEF scores was $19.83 \pm 2.2,20.39 \pm 1.35$ and 27.83 \pm 0.34 in groups $M, T, C$. When $M$ and $T$ groups were compared with group $\mathrm{C}$, there were significant differences between $\mathrm{T}$ and $\mathrm{M}$ groups and group $\mathrm{C}$, but there was no statistical difference when $\mathrm{T}$ and $\mathrm{M}$ groups were compared to each other (Table 1). When TSH, T3, T4 and testosterone levels were compared between groups, we identified no significant difference. There was a negative correlation between age and IIEF. We found no correlation with headache duration, testosterone level in $\mathrm{M}$ and T groups.

While $6.66 \%$ of patients in group $M$ had IIEF values below $10,60 \%$ of the patient values were between 11 and $22.3 .22 \%$ of patients in group $\mathrm{T}$ had IIEF values below 10, and $51.61 \%$ of the patients in this group had values between $17-22$. In group $M$, there were no significant statistical differences between intermediatesevere sexual dysfunction groups and mild-intermediate sexual dysfunction groups in terms of total testosterone levels. Similarly, in group $\mathrm{T}$, there were no significant statistical differences between intermediate-severe sexual dysfunction groups and mild-intermediate sexual dysfunction groups in terms of total testosterone levels (Table 2). Additionally, Beck Depression Scores were not significantly different in groups $M, T$ and $C(p=0.51)$ (Table 1). Other socio-demographic characteristics of the groups were expressed in Table 3.

\section{Discussion}

Erectile dysfunction is an important health problem that increases in prevalence with advancing age. It negatively affects patients' and their partners' social lives and mental health. Erection is based on central, hormonal and peripheral factors. The primary event in erection is after sexual arousal, following relaxation of smooth muscles 
Table 1 Age, BDS, IIEF and BMI scores, Testosterone levels in Migraine, TTH and control groups

\begin{tabular}{|c|c|c|c|c|}
\hline & Migraine & $\mathrm{TTH}$ & Control & $F$ and $p$ \\
\hline \multirow[t]{2}{*}{ Age (Year) } & $34.96 \pm 1.30$ & $35.54 \pm 1.52$ & $32.26 \pm 1.38$ & $F=1.53$ \\
\hline & & & & $p=0.22$ \\
\hline IIEF & $19.83 \pm 2.2$ & $20.39 \pm 1.35$ & $27.83 \pm 0.34$ & $\begin{array}{l}F=16.95 \\
\mathbf{p}=\mathbf{0 . 0 0 1}\end{array}$ \\
\hline Testosterone & $4.82 \pm 0.37$ & $4.51 \pm 0.34$ & $4.59 \pm 0.30$ & $p=0.37$ \\
\hline BMI $\left(\mathrm{kg} / \mathrm{m}^{2}\right)$ & $24.68 \pm 0.56$ & $27.06 \pm 0.79$ & $25.85 \pm 0.49$ & $p=0.56$ \\
\hline BDS & $2.86 \pm 3.31$ & $4.06 \pm 4.02$ & $3.50 \pm 4.14$ & $p=0,51$ \\
\hline
\end{tabular}

IIEF: International Index of Erectile Function, BMI: Body Mass Index, TTH: Tension type headache, BDS: Beck Depression Scores.

in the corpus cavernosum, and the filling of sinusoids with blood. As a result of cavernosal neural crest stimuli and parasympathetic stimuli from preganglionic neurons in the intermediolateral columns in S2-4, neurogenic and endothelial nitric oxide are released. This is followed by a reaction that contains L-arginine tetrahydrobiopterin. As a result of this reaction, lipophilic nitric oxide is produced and enters the cavernosal smooth muscle cells. cGMP decreases $\mathrm{Ca}^{+2}$ levels by different mechanisms, then initiates and mediates the erection by relaxing cavernosal smooth muscles. As understood, erection is a complex process including vascular structures, peripheral and central mediators and neural system [12-15].

As mentioned in the guidelines neurogenic, organic, vascular and endocrinologic etiologies can result in ED [16]. In addition, personal mental system and related psychogenic reasons also take part in the etiology of ED [17]. It is known that systemic and chronic disorders are included in ED etiology [18-20]. In this context, Sasaki et al. found a $90 \%$ prevalence of ED in a study that monitored 1118 cases with a diagnosis of Diabetes Mellitus (DM) [21]. Also Giuliano et al. from France found a 71\% prevalence in a study of 7689 DM patients [22]. MS, a chronic systemic disease that affects young sexually active men, is reported in ED etiology and Thoma et al. found a $50-90 \%$ prevalence in a study with MS patients [23]. Headaches were investigated for their effects on sexual life in many studies. In Taiwan, 5362 ED patients were investigated for migraine, and compared to the control group it was found statistically increased especially in the 30-39 age range [24]. In another study, sexual dysfunction was found more often in patients with migraines, and pathogenesis was associated with serotonin [25]. In a study of Timothy et al. migraine was compared with tension type headache in terms of sexual dysfunction and it was found more often in the tension type headache group [26]. Our results were consistent with the literature: each headache group was found statistically significant for sexual dysfunction compared to control group. However there were no significant differences between group $\mathrm{M}$ and $\mathrm{T}$.

Several mechanisms are suggested for the cause of ED via systemic and chronic disorders. According to this, primary chronic disease can affect the vascular structures and corpus cavernosum or cavernosal neurons that are important for erection. It is suggested that ED can be caused by Multiple Sclerosis (MS) or neurogenic diseases by affecting cavernosal and pelvic neurons, DM by effecting cavernosal smooth muscle or vascular muscle structures or peripheral neuropathy. It is also known that mood disorders caused by chronic diseases can cause ED. Treatment methods or psychological states of these systemic or chronic diseases can cause sexual dysfunction indirectly. In a study that contained $17 \mathrm{MS}$ cases, psychiatric disorders were found in 12.56\% [27] and in another study psychiatric disorders were found in $38 \%$ of patients with eosinophilic fasciitis [28]. Even though it is known that chronic diseases can cause psychiatric disorders by causing mood disorders, the number of studies that examine relations of these diseases with ED are limited. In a study that included 100 male cases of Brucellosis between ages 20-45, ED was found in $68 \%$ [29].

Table 2 International index of erectile dysfunction (IIEF) scores in groups

\begin{tabular}{|c|c|c|c|c|c|c|}
\hline \multirow[b]{2}{*}{ IIEF } & \multicolumn{2}{|c|}{ Migraine } & \multicolumn{2}{|c|}{ Tension type } & \multicolumn{2}{|c|}{ Control } \\
\hline & $\mathbf{n}$ & $\%$ & $\mathbf{n}$ & $\%$ & $\mathbf{n}$ & $\%$ \\
\hline No sexual dysfunction (23-30) & 10 & 33.33 & 14 & 45.16 & 30 & 100 \\
\hline Mild-Intermediate Sexual Dysfunction (11-22) & 18 & 60.00 & 16 & 51.61 & 0 & 0 \\
\hline Severe Sexual Dysfunction $(\leq 10)$ & 2 & 6.66 & 1 & 3.22 & 0 & 0 \\
\hline Total & 30 & 100 & 31 & 100 & 30 & 100 \\
\hline
\end{tabular}


Table 3 Comparison of research groups according to sociodemographic factors

\begin{tabular}{|c|c|c|c|c|c|c|c|c|}
\hline \multicolumn{2}{|r|}{ Features } & \multicolumn{2}{|c|}{ Migraine } & \multicolumn{2}{|c|}{ Tension type } & \multicolumn{2}{|c|}{ Control } & \\
\hline & & $\mathrm{n}$ & $\%$ & $\mathbf{n}$ & $\%$ & $\mathbf{n}$ & $\%$ & \\
\hline \multirow[t]{2}{*}{ Education } & Primary school & 17 & 56.6 & 20 & 64.5 & 15 & 50 & $x^{2}=0.73 ; p=0.25$ \\
\hline & High school and above & 13 & 43,3 & 11 & 35,5 & 15 & 50 & \\
\hline \multirow[t]{3}{*}{ Period of disease } & 0-5 year & 13 & 43.3 & 18 & 58.1 & - & - & $x^{2}=2.12 ; p=0.73$ \\
\hline & 6-10 year & 13 & 43.3 & 8 & 25.8 & - & - & \\
\hline & 10 and more & 4 & 13.3 & 5 & 16.1 & - & - & \\
\hline \multirow[t]{2}{*}{ Income } & Intermediate & 27 & 90.0 & 28 & 90.3 & 23 & 76,7 & $x^{2}=2.99 ; p=0.65$ \\
\hline & Good & 3 & 10.0 & 3 & 9.7 & 7 & 23.3 & \\
\hline \multirow[t]{2}{*}{ BMI $\left(\mathbf{k g} / \mathbf{m}^{2}\right)$} & Normal $(<24,9)$ & 16 & 53.3 & 10 & 32.3 & 9 & 30.0 & $x^{2}=4.22 ; p=0.56$ \\
\hline & Overweight and obese $(\geq 25)$ & 14 & 46.7 & 21 & 67.7 & 21 & 70.0 & \\
\hline
\end{tabular}

Chronic benign or malignant diseases or their treatments may cause sexual disorders in patients because of despair, desperation, guilt, and fear of death or pain. Also, during chronic diseases just like mental and physical energy, sexual energy correlates with survival or coping with chronic diseases [13]. Underlying mechanisms of chronic diseases such as migraine, irritable bowel syndrome, and interstitial cystitis were explained with different deregulations in central nervous system. It is suggested that this mechanism is related to the one that causes sexual dysfunction [24,26,30,31]. Current researches show that chronic pain activates much different mechanisms than acute pains. Therefore, complications with chronic pain might start a common set of processes in central nervous system and this complicated processes involves neurotransmitters, such as serotonin, dopamine [24]. It is possible that deregulations in dopamine pathways, which plays an important role especially in etiopathogenesis of migraine, affect the sexual functions negatively $[24,30,31]$. It is also suggested that, increase in the amount of serotonin (5-HT) in mid-brain can cause sexual dysfunction by having an antagonist effect on testosterone of male migraine patients $[25,26]$. The high rates of comorbidity between 'Primary headache associated with sexual activity' and migraine (25\%), as well as TTH (45\%) is also known [32]. Thus, the thought of triggering or increasing the headache during sexual activity, might be affecting the sexual performance of the patients negatively. In migraine cases, this disorder affects patients' mental state and cause ED. The studies indicates that depression and the other psychiatric disorders, which are known to cause SD, can often accompany migraine and TTH $[24,33]$. However, compared to the control group, Beck Depression Scores were not significantly different in groups $\mathrm{M}$ and $\mathrm{T}$ in our study. This result suggests, comorbid psychiatric condition alone cannot explain the sexual function disorder in both types of headache.

\section{Conclusions}

In our study, IIEF scores of patients with both migraine and tension type headache were significantly lower compared with the control group, and no direct relation of ED with Beck depression scores and BMI was established in these patients. These results suggest that, along with the effect of chronic disease and pain, there must be other complex and heterogeneous factors exist causing the development of SD in patients with migraine and TTH. As a result, prospective, randomized studies in large populations are required for revealing the etiology of sexual dysfunction in patients with headaches.

\section{Abbreviations}

ED: Erectile dysfunction; TTH: Tension type headache; BMI: Body mass index; IIEF: International index of Erectile Function; Group M: Migraine group; Group $\mathrm{T}$ : Tension type headache group; Group C: Control group; DM: Diabetes Mellitus; MS: Multiple Sclerosis.

\section{Competing interest}

The authors declare no potential conflicts of interests with respect to the authorship and/or publication of this article.

\section{Authors' contributions}

DA, VS, YG: have made substantial contributions to conception and design, acquisition of data, analysis and interpretation of data; FE, BC: have been involved in drafting the manuscript; SGK, FE: were involved in revising the manuscript critically for important intellectual content and have given final approval of the version to be published. All authors read and approved the final manuscript.

\section{Acknowledgments}

We are very grateful to Dr. Ilker Etikan, biostatistics department of Gaziosmanpasa University.

\section{Financial disclosure/funding}

This work didn't receive any financial support.

\section{Author details}

'Department of Neurology, Gaziosmanpasa University Faculty of Medicine, Tokat, Turkey. ${ }^{2}$ Department of Urology, Gaziosmanpasa University Faculty of Medicine, Tokat, Turkey.

Received: 28 February 2013 Accepted: 21 May 2013

Published: 29 May 2013 


\section{References}

1. Eid JF, Nehra A, Andersson KE, Heaton J, Lewis RW, Morales A, Moreland RB, Mulcahy JJ, Porst H, Pryor JL, Sharlip ID, Wagner G, Wyllie M (2000) First international conference on the management of erectile dysfunction. Overview consensus statement. Int J Impot Res 12(Suppl 4):2-5

2. Feldman HA, Goldstein I, Hatzichristou DG et al (1994) Impotance and its medical and psychosocial correlates: results of the Massachusetts Male Aging Study. J Urology 151:54-61

3. Rosen R, Altwein J, Boyle P (2003) Lower urinary tract symptoms and male sexual dysfunction: The multinational survey of the aging male (MSAM-7). Eur Urol 44:637-649

4. Kessler TM, Fowler CJ, Panicker JN (2009) Sexual dysfunction in multiple sclerosis. Expert Rev Neurother 9:341-350

5. Shiri R, Koskimäki J, Hakama M, Häkkinen J, Tammela TL, Huhtala H, Auvinen A (2003) effect of chronic diseases on incidence of erectile dysfunction. Urology 62:1097-1102

6. Thomas E, Koumouvi K, Blotman F (2000) Impotence in a patient with rheumatoid arthritis treated with methotrexate. J Rheumatology 27:1821-1822

7. Tamler R (2009) Diabetes, obesity, and erectile dysfunction. Gend Med 6 (Suppl 1):4-16

8. Hashizume M, Yamada U, Sato A et al (2008) Stress and psychological factors before a migraine attack: A time-based analysis. Biopsychosoc Med 2:14-18

9. Althof SE (2002) Quality of life erectile dysfunction. Urology 59:803-810

10. Amidu N, William KBA, Owiredu EW, Appiah R, Quaye L, Gyasi-Sarpong, CK (2010) Sexual dysfunction among Ghanaian men presenting with various medical conditions. Reprod Biol Endocrinol 8:118

11. Rosen RC, Riley A, Wagner G, Osterloh IH, Kirkpatrick J, Mishra A (1997) The international index of erectile function (IIEF): a multidimensional scale for assessment of erectile dysfunction. Urology Jun 49(6):822-830

12. Akkus E, Kadioglu A, Esen A (2002) Prevalence and correlates of erectile dysfunction in Turkey: a population-based study. Eur Urol 41:298-304

13. Lincoln TM (1989) Cyclic GMP and mechanism of vasodilatation. Pharmacol Ther 41:479-502

14. Lue TF (2005) Physiology of penile erection and pathophysiology of erectile dysfunction and priapism in: Campbell' Urology $8^{\text {th }}$ edition, Philadelphia. Saunders 45:1591-1618

15. Lue TF (2000) Erectile dysfunction. N Engl J Med 342:1802-1813

16. Lewis RW (2001) Epidemiology of erectile dysfunction. Urol Clin North Am 28:209-216

17. Sugimori H, Yoshida K, Tanaka T, Baba K, Nishida T, Nakazawa R, Iwamoto T (2005) Relationships between erectile dysfunction, depression, and anxiety in Japanese subjects. Sex Med 2:390-396

18. Lee SW, Liong ML, Yuen KH, Leong WS, Cheah PY, Khan NA, Krieger JN (2008) Adverse impact of sexual dysfunction in chronic prostatitis/chronic pelvic pain syndrome. Urology 71:79-84

19. Kummer A, Cardoso F, Teixeira AL (2009) Loss of libido in Parkinson's disease. Sex Med 6:1024-1031

20. El-Sakka Al, Hassoba HM, Sayed HM, Tayeb KA (2005) Pattern of endocrinal changes in patients with sexual dysfunction. J Sex Med 2:551-558

21. Sasaki H, Yamasaki H, Ogawa K, Nanjo K, Kawamori R, Iwamoto Y, Katayama S, Shirai M (2005) Prevalence and risk factors for erectile dysfunction in Japanese diabetics. Diabetes Res Clin Pract 70:81-89

22. Giuliano FA, Leriche A, Jaudinot EO, de Gendre AS (2004) Prevalence of erectile dysfunction among 7689 patients with diabetes or hypertension, or both. Urology 64:1196-1201

23. Kessler TM, Fowler CJ, Panicker JN (2009) Sexual dysfunction in multiple sclerosis. Expert Review of Neuro therapeutics 9:341-350

24. Huang CY, Keller JJ, Sheu JJ, Lin HC (2012) Migraine and erectile dysfunction: Evidence from a population-based case-control study. Cephalalgia 32:366-372

25. Sicuteri F, Del Bene E, Fonda C (1976) Sex, migraine and serotonin interrelationships. Monogr Neural Sci 3:94-101

26. Houle TT, Dhingra LK, Remble TA, Rokicki LA, Penzien DB (2006) Not Tonight, I Have a Headache? Headache 46:983-990

27. Alajbegovic A, Loga N, Tiro N, Alajbegovic S, Cindro V, Hozo I (2009) Cognitive and depressive disorders in multiple sclerosis. Acta Clin Croat 48:3-8

28. Kroft EB, deJong EM, Evers AW (2009) Psychological distress in patients with morphea and eosinophilic fasciitis. Arch Dermatol 145:1017-1022
29. Kassur B, Dziubek Z (1980) Andrologic studies and sexual potency in chronic human brucellozis. Infection 8:94-97

30. Hull EM, Muschamp JW, Sato S (2004) Dopamine and serotonin: influences on male sexual behavior. Physiol Behav 15:291-307

31. Rollene NL, Khan Z, Schroeder DR, Cutrer FM, Coddington CC (2011) Migraines and ovarian hyperstimulation syndrome: a dopamine connection. Fertil Steril 95:417-419

32. Frese A, Eikermann A, Frese K, Schwaag S, Husstedt IW, Evers S (2003) Headache associated with sexual activity: demography, clinical features, and comorbidity. Neurology 61(6):796-800

33. Beghi E, Bussone G, D'Amico D, Cortelli P, Cevoli S, Manzoni GC, Torelli P, Tonini MC, Allais G, De Simone R, D'Onofrio F, Genco S, Moschiano F, Beghi M, Salvi S (2010) Headache, anxiety and depressive disorders: the HADAS study. J Headache Pain 11(2):141-150

doi:10.1186/1129-2377-14-46

Cite this article as: Aksoy et al:: The evaluation of sexual dysfunction in male patients with migraine and tension type headache. The Journal of Headache and Pain 2013 14:46.

\section{Submit your manuscript to a SpringerOpen ${ }^{\odot}$ journal and benefit from:}

- Convenient online submission

- Rigorous peer review

- Immediate publication on acceptance

- Open access: articles freely available online

- High visibility within the field

- Retaining the copyright to your article

Submit your next manuscript at $\gg$ springeropen.com 